\title{
PEMANFAATAN PEKARANGAN PERUMAHAN KOTA DENGAN PROGRAM LINGKUNGAN RUMAH TOGA DAN PANGAN
}

\author{
Adi Budiwan ${ }^{1}$ \\ Universitas Wijaya Putra \\ adibudiwan@uwp.ac.id
}

\begin{abstract}
Abstrak
LRTP merupakan lingkungan toga dan pangan. Diversifikasi pangan melalui pemanfaatan lahan pekarangan berbasis sumberdaya lokal. Selain itu juga dikembangkan konsep pangan yang ramah lingkungan dan mandiri untuk pemenuhan kebutuhan keluarga, serta efisiensi pengeluaran keluarga. Konsep ini perlu dilakukan agar program LRTP bisa memasyarakat ke seluruh warga di desa Babat Jerawat, dengan tujuan : (1) Memasyarakatkan dan mengajak masyarakat desa Babat Jerawat untuk membuat Lingkungan Rumah Toga dan Pangan (LRTP). (2) Terbentuknya kelompok lingkungan yang bisa mendukung pelaksanaan (LRTP), maupun program-program lain. Pelatihan dilakukan di RT 03 dan 04 desa Babat Jerawat, kecamatan Pakal, Surabaya dengan pendekatan partisipatoris menggunakan dorongan dan ajakan terhadap karang taruna setempat. Hasil koordinasi menunjukkan bahwa: (1) masyarakat sangat aktif menyambut serta melaksanakan program LRTP. (2) Masyarakat telah behasil membentuk kelompok yang bernama Kelompok Toga dan Pangan (KTP), yang akan mensukseskan program LRTP lebih lanjut.
\end{abstract}

Kata Kunci : pekarangan, toga, pangan

\section{PENDAHULUAN}

Dalam rangka pemanfaatan pekarangan ataupun teras rumah pada setiap rumah tangga baik di perdesaan maupun di perkotaan, pemerintah melalui Kementerian Pertanian sejak tahun 2011 telah mencanangkan suatu program yang disebut Lingkungan Rumah Pangan dan Toga (LRPT). Dibentuknya LRPT ini melibatkan rumah tangga dalam mewujudkan kemandirian pangan, diversivikasi pangan berbasis sumberdaya lokal, dan konservasi tanaman pangan untuk masa depan. Konsep yang dikembangkan adalah kemandirian pangan melalui pemanfaatan pekarangan yang ramah lingkungan untuk pemenuhan kebutuhan pangan dan gizi keluarga, serta peningkatan pendapatan yang pada akhirnya akan meningkatkan kesejahteraan masyarakat

Dengan dimanfaatkannya pekarangan maupun teras rumah untuk membudidayakan berbagai tanaman sayur, toga maupun tanaman pangan lainnya maka artinya setiap rumah tangga penduduk bisa mencukupi atau mengurangi beban pengeluaran belanja setiap hari. Bahkan apabila hasilnya sangat bagus dan berlebihan, produksi dari pekarangan dan teras rumah tangga ini bisa dijual untuk menambah pendapatan riumah tangga. 
RT 03 dan 04 desa Babat Jerawat, kecamatan Pakal, Surabaya. Para penduduk atau setiap rumah tangga diharapkan dapat memanfaatkan setiap pekarangan atau teras rumah untuk berbagai tanaman produktif yang diharapkan dapat menghemat biaya belanja rumah tangga setiap harinya.

Pelatihan ini penting untuk dilakukan mengingat masih banyaknya masyarakat yang belum mengetahui kebaikan program LRPT, sehingga perlu didorong partisipasinya. Demikian pula masih belum ada penelitian yang khusus mengamati pelaksanaan LRPT setelah berjalan.

Hal ini perlu dilakukan mengingat begitu bagusnya tujuan LRPT yang ingin dicapai. Diantaranya adalah pemenuhan kebutuhan pangan dan gizi keluarga dan masyarakat secara lestari dalam suatu kawasan, serta mengembangkan kegiatan ekonomi produktif keluarga dan menciptakan lingkungan hijau yang sehat secara mandiri. Keberhasilan program LRPT di RT 03 dan 04 desa Babat Jerawat, kecamatan Pakal, Surabaya ini diharapkan akan menjadi acuan pelaksanaan LRPT di kelurahan lain.

Dari latar belakang masalah di atas maka masalah yang menarik untuk diteliti dan dikembangkan adalah :

Satu adalah apakah warga penduduk Arjosari bisa diajak untuk berpartisipasi langsung dalam pembangunan melalui LRPT

Dua adalah apakah warga RT 03 dan 04 desa Babat Jerawat bisa diajak menciptakan satu kawasan LRPT, serta mampu mengembangkan secara mandiri, seperti membentuk kelompok lingkungan.

Tiga adalah sejauh mana tingkat keberhasilan pelaksanaan program LRPT di RT 03 dan 04 desa Babat Jerawat..

Keempat adalah kendala apa saja yang dihadapi dalam pelaksanaan program LRPT di RT 03 dan 04 desa Babat Jerawat.

Kelima adlah apakah pengeluaran belanja rumah tangga LRPT bisa lebih hemat dibandingkan dengan pengeluaran belanja rumah tangga sebelum ikut LRPT

Target
Dari pelaihan ini diharapkan dapat menumukan suatu model LRPT yang mempunyai filter khusus diantaranya memiliki kecepatan penyebaran cepat. Model LRPT yang baru ini diharapkan bisa menjadi pilihan pemerintah atau masyarakat tentang program pengembangan program LRPT.

\section{METODE}

Metode penelitian yang digunakan dalam penelitian ini yakni dengan pendekatan metode partisipatoris, yaitu mengajak warga masyarakat responden ikut berpartisipasi aktif dan sukarela dalam proses pembangunan (Mikkelsen, 2011).

Secara tabel tahapan rancangan model LRPT di RT 03 dan 04 desa Babat Jerawat, kecamatan Pakal, Surabaya adalah sebagai berkut

\begin{tabular}{|c|c|c|c|}
\hline Kegiatan & Sasaran & Tujuan & $\begin{array}{c}\text { Capaian } \\
\text { yang } \\
\text { diharapkan }\end{array}$ \\
\hline $\begin{array}{l}\text { Menganalisa } \\
\text { situasi atau } \\
\text { kondisi }\end{array}$ & $\begin{array}{l}\text { Lokasi dan } \\
\text { penduduk } \\
\text { setempat }\end{array}$ & $\begin{array}{l}\text { Melihat profil } \\
\text { tempat penelitian } \\
\text { dan profil } \\
\text { penduduk }\end{array}$ & $\begin{array}{l}\text { Mengetahui } \\
\text { profil tempat } \\
\text { penelitian } \\
\text { dan } \\
\text { penduduk. }\end{array}$ \\
\hline $\begin{array}{l}\text { Sosialisasi } \\
\text { dan diskusi }\end{array}$ & $\begin{array}{l}\text { Penyuluh dan } \\
\text { penduduk }\end{array}$ & $\begin{array}{l}\text { Mensosialisasika } \\
\text { n } \\
\text { rencana program } \\
\text { pemasyarakatan } \\
\text { LRPT }\end{array}$ & $\begin{array}{l}\text { Penyuluh } \\
\text { dan warga } \\
\text { penduduk } \\
\text { ikut } \\
\text { berpartisipas } \\
\text { i dalam } \\
\text { program } \\
\text { pemasyaraka } \\
\text { tan } \\
\text { LRPT }\end{array}$ \\
\hline \begin{tabular}{|l|} 
Identifikasi \\
masalah- \\
masalah yang \\
berkaitan \\
dengan LRPT
\end{tabular} & $\begin{array}{l}\text { Warga } \\
\text { penduduk }\end{array}$ & $\begin{array}{l}\text { Mengidentifikasi } \\
\text { masalah-masalah } \\
\text { yang terjadi pada } \\
\text { tingkat warga } \\
\text { penduduk } \\
\text { berkaitan } \\
\text { dengan } \\
\text { penerapan } \\
\text { LRPT }\end{array}$ & $\begin{array}{l}\text { Mengetahui } \\
\text { masalah- } \\
\text { masalah } \\
\text { yang terjadi. }\end{array}$ \\
\hline \begin{tabular}{|l|} 
Merancang \\
model \\
pemasyarakat \\
an \\
LRPT
\end{tabular} & $\begin{array}{l}\text { Warga } \\
\text { penduduk }\end{array}$ & $\begin{array}{l}\text { Merancang } \\
\text { model } \\
\text { pemasyarakatan } \\
\text { LRPT dengan } \\
\text { memperhatikan } \\
\text { masalah-masalah } \\
\text { yang terjadi di }\end{array}$ & $\begin{array}{l}\text { Terbentukny } \\
\text { a rancangan } \\
\text { model } \\
\text { pemasyaraka } \\
\text { tan } \\
\text { pertanian } \\
\text { sosial yang }\end{array}$ \\
\hline
\end{tabular}




\begin{tabular}{|c|c|c|c|}
\hline & & $\begin{array}{l}\text { tingkat } \\
\text { penduduk. }\end{array}$ & $\begin{array}{l}\text { komunikatif } \\
\text { dan layak } \\
\text { secara } \\
\text { tehnis, sosial } \\
\text { dan } \\
\text { ekonomis } \\
\text { untuk } \\
\text { masyarakat } \\
\text { setempat } \\
\text { dengan } \\
\text { mempertimb } \\
\text { angkan hasil } \\
\text { penelitian } \\
\text { yang sudah } \\
\text { ada. }\end{array}$ \\
\hline $\begin{array}{l}\text { Membentuk } \\
\text { satu kawasan } \\
\text { LRPT }\end{array}$ & penduduk & $\begin{array}{l}\text { Agar di suatu } \\
\text { wilayah } \\
\text { terbentuk } \\
\text { satu kawasan } \\
\text { LRPT }\end{array}$ & $\begin{array}{l}\text { Penduduk } \\
\text { mampu } \\
\text { membentu } \\
\text { wilayahnya } \\
\text { dalam satuan } \\
\text { wilayah } \\
\text { LRPT }\end{array}$ \\
\hline $\begin{array}{l}\text { Membentuk } \\
\text { satu } \\
\text { kelompok } \\
\text { lingkungan }\end{array}$ & penduduk & $\begin{array}{l}\text { agar pelasanaan } \\
\text { LRPT bisa lestari }\end{array}$ & $\begin{array}{l}\text { penduduk } \\
\text { mampu } \\
\text { membentuk } \\
\text { satu } \\
\text { kelompok } \\
\text { lingkunag } \\
\text { yang } \\
\text { dapat } \\
\text { mendukung } \\
\text { pelaksanaan } \\
\text { dan } \\
\text { keberlanjuta } \\
\text { n LRPT }\end{array}$ \\
\hline
\end{tabular}

\section{HASIL DAN PEMBAHASAN}

\section{Hasil Pemasyarakatan Program LRPT Serta Tingkat Partisipasi Warga Terhadap Program LRPT.}

Setelah disetujuinya penelitian LRPT di RT 03 dan 04 desa Babat Jerawat, tim peneliti terus melalukan pendekatan serta sosialisasi kepada masyarakat sasaran. Mengingat penelitian ini menggunakan Partisipatoris, maka peneliti berusaha sesering mungkin berada di lokasi penelitian. Dari kondisi yang ada, masyarakat RT 03 dan 04 desa Babat Jerawat sudah meulai mengenal menanam sayuran di sekitar balai RW yang ditanam di teras atau pekarangan tanpa ada koordinasi serta kondisinya kurang baik dan tidak beraturan. Dengan dmikian peneliti bermaksud untuk lebih mengembangkan potensi dan keinginan warga lokal dengan memberikan sosialisi, contoh-contoh serta memberikan bantuan media tanam beserta bibit sayuran yang diatur sesuai rencana dalam penelitian.

Pada awalnya sosialisasi dilakukan secara lisan antar personal penduduk oleh tim peneliti yang dibantu warga setempat yang telah dilatih sebelumnya oleh peneliti. Dari cara ini ternyata renpon masyarakat cukup bagus dan banyak yang ingin ikut dan bersedia menjadi responden. Dari diskusi dan sosialisasi dengan warga setempat muncul beberapa masukan tentang jenis-jenis tanaman yang akan ditanam serta banyaknya tanaman untuk masing-masing rumah tangga responden. Usulan yang muncul misalnya tanaman cabe, terong, bayam, kangkung, dsb. Dari kesepakatan dengan warga akhirnya dipilih tiga tanaman utama yakni terong, dan cabe, jahe, kunyit, laos, daun brambang. Selanjutnya juga ditanam beberapa tanaman cepat panen seperti kangkung, bayam, dan sawi.

Dari diskusi dengan warga setempat bersaam tim peneliti akhirnya ditetapkan karang taruna responden yang dipilih menurut rencana penelitian, yakni responden yang dipilih meliputi satu RW yang terdiri beberapa RT.

Karang Taruna ini diberikan pelatihanpelatihan yang berkaitan dengan program LRPT, yang dilakukan secama individu maupun kelompok. Secara kelompok mereka dilatih di Balai RW. Sedangkan secara individual dilakukan di rumah masing-masing responden oleh petugas lapang penelitian yang telah terlatih juga oleh tim peneliti sendiri.

\section{Rancangan LRPT}

\section{a. Sistem Blok}

Model LRPT yang dikembangkan dalam penelitia ii adalah menggunakan sistem blok. Satu kawasan LRPT yang dimaksud adalah satu Rukun Warga (RW) yang terdiri dari beberapa RT. Dalam penelitian ini RW yang dipih adalah RW 01 yang terdiri dari 5 RT. Pada tahap awal, responden tidak diambil dari seluruh RT melainkan hanya diambil 2 
RT dengan Balai RW sebagai percontohan yang cukup mewakili. Dalam satu RW diwakili oleh karang taruna.

Digunakannya karang taruna hanya dari beberapa RT saja dengan maksud agar warga dari RT lain yang tidak menjadi responden semakin penasaran dan semakin tertarik ingin ikut jadi responden. Kalau hal ini terjadi maka tingkat penyebaran LRPT akan semakin cepat.

Dengan tujjuan agar hasil LRPT ini memberikan manfat ekonomi, maka Karang Taruna mendapat 50 bahan tanam yang terdiri dari media tanam dalam polybag beserta beserta 50 tanaman sayuran dan toga.Jenis sayuran ini memerlukan umur panen yang cepat panen antara lain kangkung dan bayam. Maksud penanaman kangkung dan bayam ini adalah sebagai sayuran pendahuluan yang basa dikonsumsi sementara sambil menunggu hasil panen tanaman lain.

Sampai dengan laporan PKM ini belum seluruh sayuran panen. Beberapa cabe mulai berbuah kecil, terong masih berbuah beberapa, sedangkan bayam, kangkung mulai banyak dipanen.

Dari keseluruhan tanaman sayuran yang ditanam tampak tumbuh subur dan ada harapan menghasilkan hasil panen yang cukup banyak.

Sayuran yang ditanam ini merupakan sayuran kebutuhan sehari hari sehingga memiliki nilai ekonomi yang lebih tinggi daripada sayuran an beli. Harga sayuran beli ini bias lebih tinggi $2-3$ kali dari harga sayuran anorganik.

Dengan rancangan model LRPT penelitian ini, yakni dalam satu kawasan LRPT (satu RW) terlebih dahulu hanya diambil beberapa RT saja dengan tanaman sejenis untuk dua blok RT (system blok), ternyata warga di RT lain yang tidak menjadi responden sangat banyak yang tertarik ingin mengikuti program ini. Selain dari ajakan dari responden untuk ikut program LRPT, mereka cukup tertarik melihat diteras rumah responden terdapat banyak tanaman yang tumbuh sangat subur. Sehingga banyak diantara mereka bertanya-tanya kenapa mereka tidak mendapat bibit tanaman, bahkan ketika di satu RT mereka tidak ada yang jadi responden, kok hanya dibeberapa RT saja. Kondisi ini juga menunjjukkan bahwa pemasyarakatan LRPT di RT 03 dan 04 desa Babat Jerawat cukup berhasil dan mampu mempengaruhi atau mengajak masyarakat ikut dalam program LRPT.

Namun keinginan masyarakat banyak di RT 03 dan 04 desa Babat Jerawat belum bisa terpenuhi semuanya. Salah sat kendalanya adalah sulitnya mencari bahan tanam (terutama media tanam).

\section{b. Sistem Ajakan dan Dorongan.}

Mengingat metode peelitian yang digunakan adalah partisipatoris, dimana tim peneliti cukup intensif berada di lokasi penelitan sepanag penelitian berlangsung, maka peneliti bisa mengetahui potensi pertanian yang dimiliki oleh masyarakat yang sekiranya bisa didorong lebih maju dengan melakukan ajakan. Cara dorongan dan ajakan ini ternyata cukup bagus direspon oleh masyarakat. Artinya tim peneliti tidak menggurui masyarakat, tetapi analisis potensi lokasi dan menyampaikan kepada masyarakat untuk mengembangkan lebih baik lagi. Karena ini penelitin yang didanai pemerintah, maka tim peneliti memfasilitasi semua kebutuhan warga yang berkaitan dengan usaha pengembangan potensi yang ada.

Model dorong dan ajak ini sangat direspon dengan baik, sehingga masyarakat banyak yang ingin ikut program LRPT. Dari mereka juga mulai kreatif dan banyak yang menyampaikan ususl-usul tentang pengembangan program-program LRPT.

Responden yang telah diberi bahan tanam juga semakin aktif melakukan ajakan kepada warga lain yang belum mengetahui apa maksud program LRPT yang mereka ikuti. Sampai dengan PKM ini ditulis, sudah ada 16 warga dari RT lain di luar RT percontohan yang telah bergabung dalam program LRPT. Artinya tidak sampai satu pelaksanaan LRPT di RT 03 dan 04 desa Babat Jerawat, LRPT telah menyebar keseluruh RW Kelurahan Arjosari warganya terlibat dalam pelaksanaan LRPT.

Denagn cara dorongan dan ajakan ini ternyata program LRPT bisa lebih cepat meluas ke beberapa warga. Sehingga diharapkan dengan berjalannya waktu maka intensitas perluasan LRPT akan semakin tinggi sehingga tidak hanya satu RW saja yang melakukan LRPT tetapi seluruhnya 


\section{KESIMPULAN}

Tujuan memasyarakatka dan mengajak partisipasi aktif masyarakar kelurahan Arjosari untuk mengikuti program Lingkungan Rumah Pangan dan Toga (LRPT) cukup berhasil dan masyarakat sangat aktif menyambut serta pelaksanakan program LRPT.

Rancangan LRPT penelitian dengan model Blok, dimana satu kawasan LRPT adalah satu RW dengan mendahulukan beberapa RT saja yang menjadi responden beserta jenis tanaman utama dalam bentuk blok tanam, juga dengan mengajak salah satu warga menjadi anggota tim peneliti, serta dengan menggunkan sistem dorongan dan ajakan, ternyata bisa mempercepat perluasan program LRPT.

Dari partisipasi aktif warga RT 03 dan 04 desa Babat Jerawat terhadap program LRPT mereka telah behasil membentuk kelompok lingkungan, yang bertugas meneruskan dan memperluas program-program LRPT lebih lanjut.

Cukup banyak kendala yang menghambat pelaksanaan LRPT, diantaranya kendala biofisik seperti warga tidak punya pekarangan, kesulitan air, kesulitan mencari media tanam, pupuk organic, dan bibit tanaman. Demikian pula terdapat kendala sosio (sumber daya manusia) seperti kurang pengalaman bercocok tnam, keterbatasan dana, kurang adanya informasi pasar, kurangya informasi teknik budidaya pertanian, serta keterbatasan dana operasional dan kelembagaan.

\section{UCAPAN TERIMAKASIH (Bila ada)}

Ucapan terimakasih disampaikan kepada Universitas Wijaya Putra yang telah memberikan kontribusi dalam pelaksanaan kegiatan. Ucapan terima kasih disampaikan kepada LPPM Universitas Wijaya Putra yang telah mengarahkan memfasilitasi PKM ini.

\section{REFERENSI}

Mikkelsen, B. (2011), Metode Penelitian Partisipatoris dan Upaya Pemberdayaan. Yayasan Pustaka Obor Indonesia, Jakarta.

Indonesia: http://setkab.go.id/berita-5945mentan-kenalkan-kawasan-rumah-panganlestari.html 